\title{
Design, synthesis and antibacterial activities of novel complexes of 3-Amino-2-Methyl-7-Chloro- Quinazolin 4 (3H)-One
}

\author{
Osarumuense Peter Osarodion \\ Dept. of Chemical Science, Ondo State University of Science and Technology, Okitipupa, Ondo State, Nigeria \\ *Corresponding Author: Osarumuense Peter Osarodion \\ Email: osarodion.peter@yahoo.com
}

\begin{abstract}
A new Ligand of 3-Amino-2-Methy-7-Chloro-Quinazolin 4(3H)-one (L) has been synthesized in good yield by the reaction of methyl-2amino-4- chlorobenzoate with acetic anhydride then the oxygen was replaced with nitrogen of hydrazine. When the Ligand reacts with Co (II), $\mathrm{Zn}$ (II) and $\mathrm{Cu}$ (II), new complexes are formed. The chemical structures of all prepared compounds were characterized by elemental analysis, IR, UV/Visible, ${ }^{1} \mathrm{H}-\mathrm{NMR},{ }^{13} \mathrm{C}-\mathrm{NMR}$, and GCMS. Moreover, molar ratio M:L was also determined. The free Ligand and their metal complexes were tested in vitrol against a number of microorganisms' gram positive bacteria (Staphylococcus aureus Bacillus species and Enterococcus feasalis), gram negative bacteria (Escherichia coli, Klebsiella pneumonia, and Pseudomonas aeruginosa) and fungi (Candida albicans) in order to assess their antimicrobial properties. All the complexes show considerable activity against all microorganisms.
\end{abstract}

Keywords: Anthranilic acid, 3-amino-2-methyl-7-chloro-quinazolin-4(3H)-one, Bioassay, Bacillus species, Metal complexes, Methyl-2amino-4-chlorobenzoate, Nucleophile; Synthesis, Antimiccrobial activity.

\section{Introduction}

Quinazolinone is an important heterocyclic ring with broad spectrum of biological activities like anticonvulsant, ${ }^{1}$ analgesic, ${ }^{2}$ antitumor, ${ }^{3}$ anti-inflammatory, ${ }^{4}$ antimicrobial, ${ }^{5}$ antitubercular, ${ }^{6}$ antioxidant ${ }^{7}$ and antiviral ${ }^{8}$ activities.

Interest in coordination chemistry is increasing continuously with the preparation of organic ligands containing a variety of donor groups. ${ }^{9-11}$ When the ligands have biological importance they are multiplied in many fold. ${ }^{12-13}$ Quinazoline compounds are widely used in agrochemicals as plant virucides ${ }^{14}$, antifungal agents ${ }^{15}$ and herbicides. ${ }^{16}$ According to recent data, quinazoline nucleus has attracted the attention of medicinal chemists due to its well known anticancer activity and many substituted quinazoline derivatives have recently earned great interest in chemotherapy as antitumor drugs. ${ }^{17,18}$

Schiff bases with donors (N, O, S, etc.) have structural similarities with natural biological systems and imports in elucidating the mechanism of transamination and reamination reaction in biological system due to presence of imine $(-\mathrm{N}=\mathrm{CH}-)$ group. $^{19}$

Taking into consideration the use of metal complexes in the treatment of some diseases mentioned above, we have tested the antimicrobial activity of a new ligand and its metal complexes using strains of Staphylococcus aureus, Bacillus species, Enterococcus feacalis, Escherichia coli, Klebsiella Pneumoniae, Pseudomonas aeruginosa and Candida albicans isolated from different pathological products of patients. Based on the above observations and in continuation of the drug research program, it was of interest to synthesize a novel metal complexes of Copper $\mathrm{Cu}(11)$, Zinc $\mathrm{Zn}(11)$ and Colbet Co (11) of the title Ligand as a trial to obtain safer and potent antibacterial agents.

\section{Experimental}

All reagents and solvents were products of sigma-Aldrich, Germany. Melting points were determined on a kofler hot stage apparatus and were uncorrected. IR spectra were recorded on a Buck scientific IR M500 instrument. The ${ }^{1} \mathrm{H}$ and ${ }^{13} \mathrm{C}$-NMR spectra were recorded in DMSO- $d 6$ at 400 $\mathrm{MH}_{\mathrm{z}}$ with HAZ VOLATILE V2. M spectrophotometer. Chemical shifts were reported in $\mathrm{ppm}$ relative to tetramethylsilane. Gas chromatography-Masss (GC/MS) spectra were obtained on a Finingan MAT $44 \mathrm{~S}$ mass spectrometer operating at electron impact energy of $70 \mathrm{eV}$. Elemental analysis data agreed favourably with the calculated values Analytical thin layer chromatography (TLC) was used to monitor the reactions.

Synthesis of 2-methyl-7-chloro-benzo [1,3] -oxazin-4one(1) and Synthesis of 3-amino-2-methyl-7-quinazolin4 (3H) one (2).

A mixture of $1.97 \mathrm{~g} \quad(0.005 \mathrm{~mol}) \quad$ Methyl-2-amino-4chlorobbenzoate or 4-chloroanthranilate with $10 \mathrm{~mL}, 1.02 \mathrm{~g}$ $(0.01 \mathrm{~mol})$ acetic anhydride in $30 \mathrm{ml}$ ethanol medium was heated under reflux with stirring using magnetic stirrer until the reaction mixture showed no trace of starting material by TLC data (about $2 \mathrm{~h}$ ). Ethanol was removed in vacuum and the solid product was recrystallized from proper solvent, Yielding $0.81 \mathrm{~g}(92 \%) \mathrm{mp}: 87-89^{\circ} \mathrm{C}$.

A mixture of equimolar amounts $(1.59,0.005 \mathrm{~mol})$ of 2methyl-2-chloro-4H-benzo[1,3]-oxazin-4-one and hydrazine hydrate $(0.93 \mathrm{~g}, 0.001 \mathrm{~mol})$ in $30 \mathrm{ml}$ boiling ethanol was heated under reflux with stirring using magnetic stirrer until the reaction mixture showed no trace of starting material by TLC data (about $3 \mathrm{~h}$ ). The white precipitate formed was then filtered, washed three times with $20 \mathrm{ml}$ of distilled water $[20 \mathrm{ml} \times 3]$. The white crystals were dried and recrystallized from dimethylformamide (DMF) to give pure 
3-amino-2-methylquinazolin-4 (3H) -one Yielding $1.48 \mathrm{~g}$ (92\%) mp: $114-116^{\circ} \mathrm{C}$.

Design, synthesis and bioassay of novel metal complexes $0.01 \mathrm{~mol}$ ) in $30 \mathrm{~mL}$ boiling ethanol was stirred using a magnetic stirrer until the reaction mixture showed no trace of starting material when TLC was developed (about $3 \mathrm{~h}$ ). The reaction mixture was concentrated in vacuum under reduced pressure using rotary evaporator. The solid product (white crystals) was dried and recrystallized from proper solvent, Yielding $1.48 \mathrm{~g}(92 \%)$; mp, $114-116^{\circ} \mathrm{C}$.

\section{Diagram}

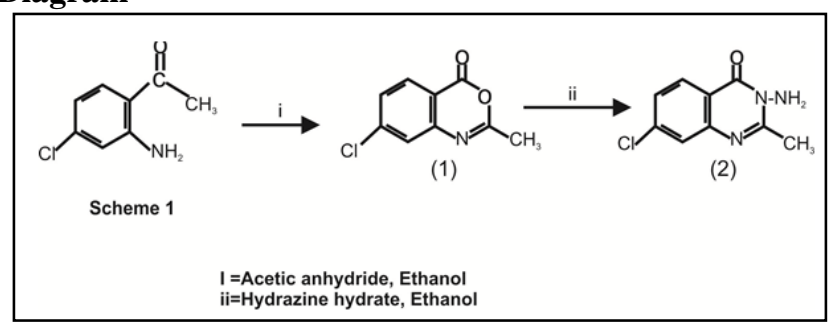

\section{Synthesis of complexes}

Reactions of the ligand with metal ions in 1: 2 molar ratio in ethanol medium yield the complexes. Ligand is bidentate in character and coordinate through oxygen and nitrogen donor atoms. All the complexes are fairly stable and can be stored for long periods at room temperature.

\section{Metal complexes synthasis}

A hot ethanolic solution $(20 \mathrm{ml})$ of corresponding metal salt $(0.005 \mathrm{~mol})$ was mixed with hot ethanolic solution of the Ligand $(0.01 \mathrm{~mole})$. The mixture was refluxed for 5 hours on a water bath on cooling the contents, a coloured complex was separated out in each case. The product was filtered, washed with $50 \%$ ethanol and dried in vacuum over $\ell_{4} \mathrm{O}_{10}$. Purity of the obtained complexes was checked by TLC. ${ }^{20}$

\section{Complexes formation in solution study}

Complexes of Ligand with metal ions were studied in solution using DMF as solvent in order to determine (M: L) ratio in the complex following the molar ratio method ${ }^{21}$. A series of solutions were prepared having a constant concentration $\left(10^{3} \mathrm{M}\right)$ of metal ion and Ligand $(\mathrm{L})$. The $(\mathrm{M} / \mathrm{L})$ ratio was determined from the relationship between the absorbance and the mole ratio of $(\mathrm{M} / \mathrm{L})$. The results are listed in Table 1.

\section{Antibacterial activity testing}

Agar wall diffusion method was utilized for the antibacterial activities ${ }^{22}$. Seven species: Staphylococcus aureus (ATCC 10145), Bacillus species (NCTC 8236), Enterococcus feacalis, (NCTC 6571), Esherishia coli (ATCC 25922), Klebsiella pneumonia (NCTC 10418), Pseudomonas aeruginosa (ATCC 10145) and Candida albicans (ATCC 24433) Stock cultures were used. The test organisms were supplied by the pharmaceutical
Microbiology Department of the University of Benin. The test organisms were cultured overnight in nutrient broth, diluted to the turbidity of McFarland standard. Broth culture $(0.5 \mathrm{~mL})$ was seeded on nutrient agar and is allowed to dry. Then various concentrations of the compound (20 $640 \mathrm{mg} / \mathrm{mL}$ ) were introduced. The culture plates were then incubated at $37^{\circ} \mathrm{C}$ for 24 hours. The results were assessed by measuring the zone of growth inhibition by the test compound $^{23}$. Activity and inactivity were observed in accordance with the standard and accepted method. Fig. 2

\section{Results and Discussion}

The reaction of the 4-chloroanthranilate or methyl-2amino4-chlorobenizoate with acetic anhydride yield the cyclic compound 2-methyl-7-chloro-4H-benzo[1,3]-oxzin-4-one (1) as shown in the mechanism. The reaction of this compound with hydrazine yields the new Ligand 3-amino-2methyl-7-chloro-quinazolin $4(3 \mathrm{H})$-one (2) as shown in the mechanism.

Antimicrobial activity of ligand and tested complexes against tested standard organization control drugs Ciprofloxicin (CPX) For Bacteria

Ketonaxol (PEF) For Fungus

Ligand (L), Complex 1 (4bCu), Complex 2 (4bZn), Complex 3 (4bCo)

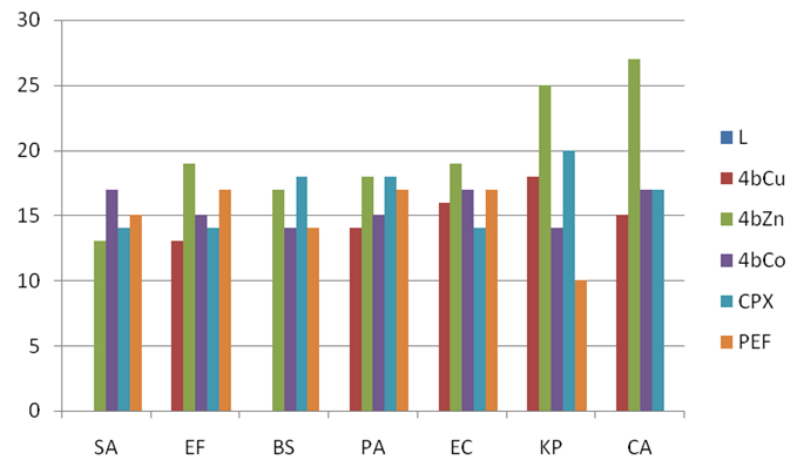

Figure 1: The effect of Ligand toward studied bacteria. SA $=$ Staphylococcus aureus, BS $=$ Bacillus species, EF = Enterococcus feacalis, $\mathrm{EC}=$ Escherichia coli, $\mathrm{KP}=$ Klebsiella pneumonia, $\mathrm{PA}=$ pseudomonas aeruginosa and $\mathrm{CA}=$ Candida albicans $(4 \mathrm{c}=\mathrm{L})$

Significantly different from Ligand at $\mathrm{P}<0.05$, values are in $\mathrm{mm}$

Table 1: Physical characteristics of complexes

\begin{tabular}{|l|l|l|c|c|c|}
\hline No & Complexes & Colour & M.P $^{\mathbf{0}} \mathbf{C}$ & $\begin{array}{c}\text { Yields } \\
(\mathbf{\%})\end{array}$ & $\begin{array}{c}\text { M: } \\
\mathbf{L}\end{array}$ \\
\hline $\mathrm{C}_{1}$ & $\mathrm{CoL}_{2} \mathrm{U}_{2}$ & Green & $\begin{array}{c}248- \\
250\end{array}$ & 82 & $1: 2$ \\
\hline $\mathrm{C}_{2}$ & $\mathrm{CuL}_{2} \mathrm{U}_{2}$ & Brown & $\begin{array}{c}250- \\
252\end{array}$ & 88 & $1: 2$ \\
\hline $\mathrm{C}_{3}$ & $\mathrm{ZnL}_{2} \mathrm{U}_{2}$ & White & $\begin{array}{c}244- \\
246\end{array}$ & 84 & $1: 2$ \\
\hline
\end{tabular}


Table 2: Elemental chemical analysis data of metal complexes

\begin{tabular}{|l|l|c|c|c|c|c|c|}
\hline \multicolumn{9}{|c|}{ Elemental Analysis } \\
\hline \multicolumn{1}{|c|}{ No } & \multicolumn{1}{|c|}{ Complexes } & \multicolumn{2}{c|}{ Theoretical Calculated Values } & \multicolumn{3}{c|}{ Actual Calculated Values } \\
\hline & & $\mathbf{C \%}$ & $\mathbf{H \%}$ & $\mathbf{M \%}$ & $\mathbf{C \%}$ & $\mathbf{H \%}$ & $\mathbf{M \%}$ \\
\hline $\mathrm{C}_{1}$ & $\mathrm{CoL}_{2} \mathrm{U}_{2}$ & 46.63 & 3.83 & 12.21 & 46.53 & 3.81 & 12.27 \\
\hline $\mathrm{C}_{2}$ & $\mathrm{CuL}_{2} \mathrm{U}_{2}$ & 45.63 & 4.83 & 12.21 & 45.33 & 4.81 & 12.30 \\
\hline $\mathrm{C}_{3}$ & $\mathrm{ZnL}_{2} \mathrm{U}_{2}$ & 47.92 & 3.45 & 13.14 & 47.82 & 3.40 & 13.00 \\
\hline
\end{tabular}

Table 3: Infrared absorption frequencies $\left(\mathrm{cm}^{-1}\right)$ of ligand and its complexes

\begin{tabular}{|l|l|c|c|c|c|c|}
\hline \multicolumn{1}{|c|}{$\mathbf{N o}$} & \multicolumn{1}{c|}{ Complexes } & $\mathbf{V}(\mathbf{N H})$ & $\mathbf{V}(\mathbf{C}=\mathbf{N})$ & $\mathbf{V}(\mathbf{C}=\mathbf{O})$ & $\mathbf{M}-\mathbf{O}$ & $\mathbf{M}-\mathbf{N}$ \\
\hline $\mathrm{C}_{1}$ & & 3340 & 1569 & 1690 & - & - \\
\hline $\mathrm{C}_{2}$ & $\mathrm{CoL}_{2} \mathrm{U}_{2}$ & 3270 & 1501 & 1630 & 448 & 442 \\
\hline $\mathrm{C}_{3}$ & $\mathrm{CuL}_{2} \mathrm{U}_{2}$ & 3210 & 1503 & 1635 & 450 & 440 \\
\hline
\end{tabular}

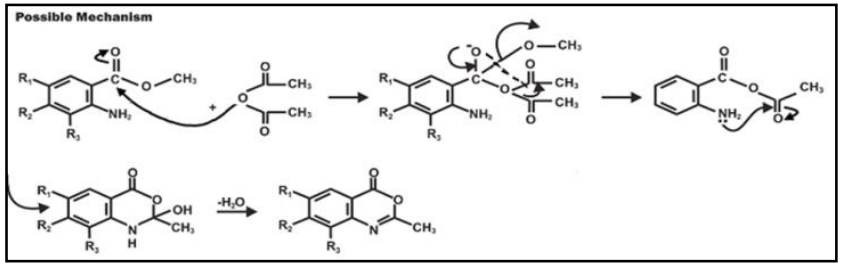

Possible Mechanism

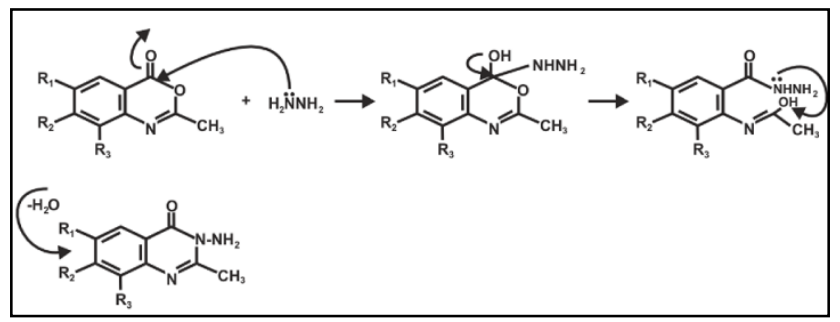

Where, $\mathbf{R}_{1}=\mathbf{H}, \mathbf{R}_{2}=\mathrm{Cl}, \mathbf{R}_{3}=\mathrm{H}$

\section{Elemental analysis}

The $\mathrm{C}, \mathrm{H}$ and $\mathrm{M}$ contents (both theoretically calculated values and actual values) are in accordance with the formula $\mathrm{ML}_{2} \mathrm{Cl}_{2}$ indicating that the ligand is neutral. This can be explained by the absence of any deprotonating agent during the synthesis. The complexes are generally soluble in common organic solvents Table 2.

\section{Infrared spectra}

The study and comparison of the IR spectra of the ligand and its complexes imply that the ligand is bidentate, with the carbon oxygen and nitrogen coordination sites. The presence of ring vibrations and $\mathrm{C}-\mathrm{H}$ absorption makes the spectra fairly complicated for complete assignment of individual bonds in Table 3. In the IR spectra of the complexes, a considerable negative shift in $\mathrm{V}(\mathrm{C}=0)$ is observed, indicating a decrease in the stretching force constant of the $\mathrm{C}=\mathrm{O}$ bond as a consequence of co-ordination through the carbonyl-oxygen atom of the free base. Another important band, which occurs at $1503 \mathrm{~cm}^{-1}$ is attributed to $\mathrm{V}(\mathrm{C}=\mathrm{N})$ azomethine mode ${ }^{24-25}$ and remain unaffected after complexation. The bond due to $\mathrm{NH}^{-}$stretching in free ligand occur in the $3340 \mathrm{~cm}^{-1}$ region, in the spectra of all the complexes. This band is shifted to lower frequency and appears in the $3200-3270 \mathrm{~cm}^{-1}$ region indicating the involvement of the $\mathrm{N}$-atom in coordination.

\section{UV-vis Spectra}

Ligand synthesized showed three absorption bands in DMF. The first band observed at $235 \mathrm{~mm}$ represents the $\left(\bar{\Lambda}-\bar{\Lambda}^{*}\right)$ transition while the second and the third bands (which have higher intensity than the first band due to conjugated system) appear at 360 and $370 \mathrm{~mm}$ and represent the $(n-\bar{\Lambda})$ transition. Generally, the bands of the newly synthesized complexes are

shifted to shorter or longer wavelengths than that of ligands, but the high intensity of these bands is indicative of complex formation. The origin of the band observed at about $700 \mathrm{~mm}$ in the electron spectra of complexes has been identified as $d-d$ transition. In these spectra the bands observed at $300-400 \mathrm{~mm}$ could be assigned to nitrogenmetal charge transfer absorption. The electronic absorption bands for the ligand and complexes are classified into two distinct groups, those belonging to liquid transitions appeared in the uv region while d-d transitions appeared in the visible region. These transitions are assigned in relevance to the structures of complexes ${ }^{20}$.

\section{Antibacterial analysis evaluation}

The antibacterial analysis results show that the synthesized compounds exhibit antibacterial activities, and it is important to note that the metal chelates exhibit more pronounced inhibitory effects than the parent ligands. The increased activity of the metal chelates can be explained on the basis of chelation theory. It is known that chelation makes the complexes more powerful and potent bactericidal agents, thus killing more of the bacteria than the ligand. It is established that, in a complex, the positive charge of the metal is partially shared with the donor atoms present in the ligands, and there may be $\bar{\Lambda}$ - electron delocalization over the whole chelate ${ }^{26}$. This increases the lipophilic character of the metal chelate and favours its permeation through the lipoid layer of the bacterial membranes. The 
increased lipophilic character of these complexes seems to be responsible for their enhanced antibacterial activity. It may be suggested that these complexes deactivates various cellular enzymes, which play a vital role in various metabolic pathways of these microorganisms. It has also been proposed that the ultimate action of the toxicant is the denaturation of one or more proteins of the cell, which as a result impairs normal cellular processes. There are other factors which also increase the activity, including solubility, conductivity and bond length between the metal and the ligand.

Activity of the ligand and metal complexes was tested against some human pathogenic microbes including Guam positive (staphylococcus aureus, Bacillus species and Enterococcus aureus), Guam negative (Escherichia coli, Klebsiella pneumonia, Pseudomonas ariginosa) and fungi (candida albicans) by the Agar wall diffusion method in Figure 2. From the result obtained from the method, it was found highly active even at low concentrations.

\section{Statistical analysis}

All data were expressed as the mean \pm SEM; the student' $s$ ttest was applied to determine the significance of the difference between the ligand and the test compounds.

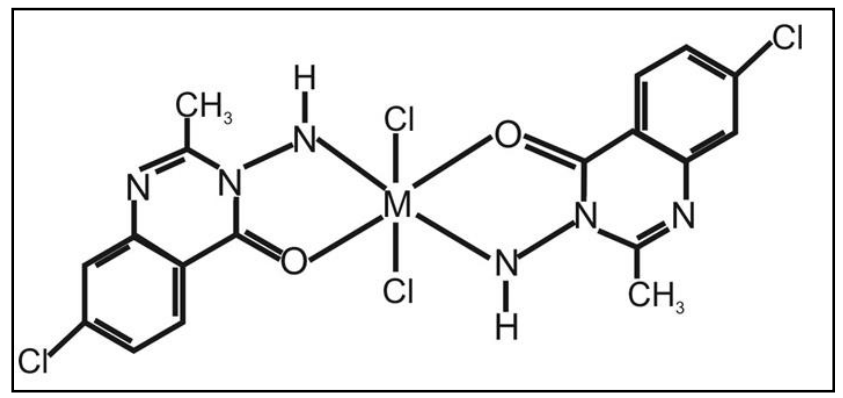

Fig. 2: Proposed structure of the complexes

\section{Conclusion}

The Ligand has a lower activity than all the synthesized complexes against the test microorganisms. From the results, we may conclude that the ligand act as bidendate uni-negative ligand, coordination through one of nitrogen and oxygen. From this study, all the complexes are found to be mononuclear, based on the IR spectroscopy data. Based on the physicochemical and the spectra studies, the tentative structures proposed for the complexes is shown in Figure 2.

\footnotetext{
Abbreviations

TLC-Thin Layer Chromatography, SEM-Standard Error Mean, IR-Infrared Spectra, UV/Visible-UV-Visible Spectra, ${ }^{1} \mathrm{H}$ NMR-Proton Nuclear Magnetic Resonance, ${ }^{13} \mathrm{C}$ NMRCarbon thirteen Nuclear Magnetic Resonance, GCMS Gas Chromatography Mass Spectroscopy, L-Ligand, 4bCuCopper complex 1, 4bZn-Zinc complex 2, 4bCu-Colbert complex 3, CPX-Ciprofloxicin, PEF-Ketonaxol.
}

\section{Conflict of interest}

The author declares no conflict of interest.

\section{Funding}

No fund was obtained during the research.

\section{Author declaration}

The author hereby declares that the work presented in this article is original and that any liability for claims relating to the content of this article will be borne by me.

\section{Ethics approval and consent to participate}

Ethic approval, consent to participate and the procedure used were approved by the Ethic approval committee of Ondo State University of Science and Technology, Okitipupa, Ondo State, Nigeria.

\section{Acknowledgement}

The author acknowledges the assistance of Baba Haruna of the Department of Pharmaceutical Chemistry of Niger Delta University, Wilberforce Island, Yenogoa and Dr. Marris, in England for running the spectra.

\section{Declaration statement}

The author declares there is no conflict of interest.

\section{References}

1. Govindaraj Saravanan, Veerachamy Alagarsamy, Chinnasamy Rajaram Prakash, Design, synthesis and anticonvulsant activities of novel 1-(substituted / unsubstituted benzylidene)4-(4- (6, 8-dibromo-2- (methyl / phenyl) -4- oxoquinazolin -3 (4H)- yl) phenyl) semicarbazide derivatives, Bioorganic \& Medicinal Chemistry Letters 2012;22:3072-8.

2. Alagarsamy V, Rajasolomon V, Meena R and Ramseshu KV. Synthesis, analgesic, anti-inflammatory and anti-bacterial activities of some novel 2-butyl 3-substituted quinazolin4(3H)-ones. Biol Pharm Bull 2005;28(6):1091-4.

3. Cao S L, Feng Y P, Jiang Y Y, Synthesis and in vivo antitumour activity of $4(3 \mathrm{H})$-qunazolinone derivatives with dithiocarbamate side chains. Bio Org Med Chem 2005;15:1915-7.

4. Alagarsamy V, "Synthesis, Analgesic and Antiinflammatory Activities of Some Novel 2, 3- Disubstituted Quinazolinone-4 (3H)-one," Biol Pharm Bull 2003;26(4):557-9.

5. Kant P. Synthesis and anti-microbial activities of some new 2substituted 3(1"e-aryl-4"e-nitrophenyl imidazol-5"e-yl) amino quinazolin-4-ones. Indian J Heterocycl Chem 2006;15:221-4.

6. Nandy P, Vishalakshi MT and Bhat AR. Synthesis and antitubercular activity of mannich bases of 2-methyl 3Hquinazolin-4-ones. Indian J. Heterocycl. Chem 2006;15:293-4.

7. Rajasekaran S, GopalKrishna R, Sanjay Pai PN and Gurpreet Singh S. Synthesis, Antibacterial and invitro Antioxidant Activity2,3-Substituted Quinazolin-4(3H)-ones. J Chem Pharm Res 2010;2(1):482-8.

8. Kumar KS, Ganguly S, Veerasamy R, Clercq ED, "Synthesis, antiviral activity and cytotoxicity evaluation of Schiff bases of some 2-phenyl quinazoline-4(3)H-ones." Eur J Med Chem 2010;45:5474-9.

9. Hancock RD, Martell AE. Ligand design for selective complexation of metal ions in aqueous solution. Chem Rev 1989;9:1875-914.

10. Bhyrappa P, Young JK, Moore JS, Suslick KS. DendrimerMetalloporphyrins: Synthesis and Catalysis. J Am Chem Soc 1996;118:5708-11. 
11. 11.Castillo-Blum SE, Barba-Behrens N. Coordination chemistry of some biologically active ligands. Coord Chem Rev 2000;196:3-30.

12. Mohan G, Rajesh N Synthesis and anti-inflammatory activity of N-pyridinobenzamide-2-carboxylic acid and its metal chelates. Indian J Pharm 1992;24:207-11.

13. Kong D, Reibenspies J, Mao J, Clearfield A. Novel 30membered octaazamacrocyclic ligand: synthesis, characterization, thermodynamic stabilities and DNA cleavage activity of homodinuclear copper and nickel complexes. Inorg Chim Acta 2003;342:158-70.

14. Hung RQ, Li HY, Ma JA, Qiu DW (1996). Synthesis of O-(4Quinazolinyl) oxime Ethers and Their Antiviral Activity. Chem J Chin Univ 1996;17:571-5.

15. Dandia A, Singh R, Sarawagi P. Green chemical multicomponent one-pot synthesis of fluorinated 2,3disubstituted quinazolin-4(3H)-ones under solvent-free conditions and their antifungal activity. J. Fluorine Chem. 125, 1835-1840 (2004).

16. Khan IA, Hassan G, Khan MA. Efficacy of Post-emergence Herbicides for controlling Weeds in Canola. Asian J Plant Sci 2003;2:294-6.

17. Jin Y, Li HY, Lin LP, Tan JZ, Ding J, Luo XM et al, Synthesis and antitumor evaluation of novel 5-substituted-4-hydroxy8nitroquinazolines as EGFR signaling-targeted inhibitors. Bioorg Med Chem 2005;13:5613-22.

18. Wissner A, Berger DM, Boschelli DH, Floyd MB Jr, Greenberger LM, Gruber BC et al., 4- Anilino-6,7dialkoxyquinoline-3-carbonitrile Inhibitors of Epidermal Growth Factor Receptor Kinase and Their Bioisosteric
Relationship to the 4-Anilino-6,7-dialkoxy- quinazoline Inhibitors. J Med Chem 2000;43:3244-56.

19. E. Keskioglu, A. Balaban Gunduzalp, and S. F. Cete, Spectrochem. Acta A, 2008;70:634-40.

20. Osarodion Orarumwense.,Lucky Okunrobo, (2015). Design synthesis and bioassay of novel metal complex of 3-amino 6,8dibromo-2-methy quinazolin-4(3H)-One. Pharm Chem J 48:(11):718-21

21. Nada A.M.A, Alkady M.Y, and Fakry H.M. Bioresources. 2007;3(1):46-59.

22. Okeke M. 1, Iroegbu C.U, Eze E.N, Okoli A.S, Esimone C.O. Evaluation of extracts of the root of Landolphia owerriensefor antibacterial activity. J Ethnopharmacol 2001;78:119-27.

23. Mackie R, McCartney. Practical Medicinal Microbiology $3^{\text {rd }}$ edition, Vol.2 Churchill Livingstone (Publishers), London and New York. 1984;121(141):100-106.

24. Radhakrishnan P, Lingegomda V, Molagavalli V., Zoures Wang Zar F.A. Positive PPD test in health-care workers (HCW). A study of the compliance of antibiotic prophylaxis. $J$ Gen Intem Med 20002;17(15):209.

25. Agarwal R.K, Prakash J. Reactions of Imine-oxime Ligands. Polyhedron 1O, 2567.(1991).

26. Om Prakash, Soumitra, K.S, Chandra, M.T. "Reactions of $\mathrm{Cp}_{2} \mathrm{MC}_{2}(\mathrm{M}=\mathrm{Ti}$ or $\mathrm{Zr}$ ) with Imine - Ozime Ligands. Formation of Metallacycles" Molecules 2005;10:653-8.

How to cite: Osarodion P.O. Design, synthesis and antibacterial activities of novel complexes of 3-Amino-2Methyl-7-Chloro-Quinazolin 4 (3H)-One. IP Int $J$ Comprehensive Adv Pharmacol 2020;5(1):37-41. 